\title{
Factors associated with contraceptive use and initiation of coital activity after childbirth
}

This article was published in the following Dove Press journal:

Open Access Journal of Contraception

20 August 2010

Number of times this article has been viewed

\author{
John E Ekabua' \\ Kufre J Ekabua ${ }^{2}$ \\ Patience Odusolu' \\ Chritopher U Iklaki' \\ Thomas U Agan' \\ Aniekan J Etokidem ${ }^{2}$ \\ 'Department of Obstetrics and \\ Gynecology, University of Calabar \\ Teaching Hospital, Calabar, Cross \\ River State, Nigeria; ${ }^{2}$ Department of \\ Community Medicine, University of \\ Calabar Teaching Hospital, Calabar, \\ Cross River State, Nigeria
}

\begin{abstract}
The aim of the study is to identify the factors influencing contraceptive use and initiation of sexual intercourse after childbirth. This was a cross-sectional descriptive survey involving 256 consecutive women, who delivered between April and October, 2007, presenting at the Immunization Clinic, University of Calabar Teaching Hospital, Nigeria in April, 2008. Data was obtained using an interviewer-administered structured questionnaire. Women who had antenatal and postnatal counseling were significantly more likely to use contraceptives than those who did not have counseling (odds ratio (OR) $0.29 ; 95 \%$ confidence interval (CI) $0.14-0.59 ; P=0.0002$ and OR $0.18 ; 95 \%$ CI $0.08-0.38 ; P=0.0000002$ respectively). Other variables significantly associated with contraceptive use included education $(P=0.0470)$ and reproductive goal $(P=0.0303)$. Linear regression analysis showed direct relationship between caesarean section and episiotomy as modes of delivery, and initiation of coitus $\left(r^{2}=0.439\right.$ and 0.45 respectively). Concerning residence after childbirth, staying at home and with in-laws showed direct relationship with initiation of coitus $\left(r^{2}=0.208\right.$ and 10.750 respectively). The number of women abstaining from intercourse showed a decreasing trend with increasing months after childbirth. Initiation of coitus was significantly associated with resumption of menstruation $(P<0.0001)$ and non-contraceptive use $(P=0.0089)$. In conclusion, this study shows the need for use of postpartum contraception before fecund women become susceptible to pregnancy.
\end{abstract}

Keywords: postpartum contraception, factors affecting use

\section{Introduction}

Postpartum contraception is defined as the initiation and use of a contraceptive method after childbirth or abortion, but before fertility returns. ${ }^{1}$ After childbirth a woman has special needs, which include the challenge of caring for her newborn, recovery from pregnancy and delivery, and the desire to space or limit childbirth. ${ }^{2}$ In spite of these specific needs, little attention is paid to postpartum contraception. In 2 Kenyan hospitals, $92 \%$ of postpartum women reported that they needed contraception, but only $2 \%$ left the hospital with a method after delivery. ${ }^{3}$ Worldwide, about one third of women with an urgent need for family planning are pregnant or have recently given birth. ${ }^{4}$ The provision of quality family planning services in the postpartum period significantly reduces maternal and child mortality and morbidity, as well as prevent the risk of unwanted pregnancies and unsafe abortion. ${ }^{5}$ In many countries, postpartum family planning services are not well integrated into existing health services, and most health delivery services do not address women's needs after pregnancy, including the provision of family planning counseling and contraception. ${ }^{6}$ In Nigeria, the median duration of postpartum amenorrhea, abstinence, and insusceptibility are 13 months,
PO Box 2522, General Post Office,

Calabar Road, Calabar,

Cross River State, Nigeria

Tel +2348053359I2I; +234 7035203645

Email johnekabua@yahoo.com 
3 months, and 15 months, respectively; with the proportion of women abstaining from intercourse decreasing with increasing months after delivery, particularly during the first year after birth. ${ }^{7}$ The framework of this study is based on what women in Nigeria do when they become susceptible to pregnancy after childbirth. This is related to 3 concepts, which are defined below for purpose of clarity:

- 'Postpartum amenorrhea' refers to the interval between childbirth and the return of menstruation. This is the period during which a woman becomes temporarily infecund following childbirth.

- 'Postpartum abstinence' refers to the period of voluntary sexual inactivity after childbirth.

- Women are considered 'insusceptible' if they are not exposed to the risk of pregnancy, either because they are amenorrheic or are abstaining from sexual intercourse following a birth.

- 'Unmet contraceptive need' is the proportion of fecund women who wish to space their next birth or to limit childbearing altogether but are not using contraception.

This study is designed to identify the factors influencing contraceptive use and resumption of sexual intercourse after childbirth in Calabar, Nigeria.

\section{Setting}

The study was carried out in Calabar, the capital of Cross River State in the South-South geopolitical zone of Nigeria. The total population of the area is 418,652 , with majority of the workforce being in government employment and of the Christian faith. Cross River State is ranked as an educationally disadvantaged state in Nigeria. The area hosts a second generation Teaching Hospital, which is a referral center for other health institutions in the geopolitical zone. The Department of Obstetrics and Gynecology was established in 1979. The setting of this study was the Immunization Clinic, which shares the same roof with the Family Planning Clinic, of the University of Calabar Teaching Hospital, Calabar.

\section{Method}

A minimum sample size of 174 was calculated from a prevalence of $13 \%$ of women using contraception in Nigeria, ${ }^{7}$ at alpha level of $5 \%$. This was a cross-sectional descriptive survey involving 256 consecutive women who delivered between April and October, 2007, and presented with their babies for immunization in April, 2008, at the University of Calabar Teaching Hospital, Calabar. Research reviews fulfilled the institution's ethical requirements. Women whose last confinement was less than 6 months and more than 1 year were excluded from the study. Eligible women for this survey where those whose last confinement was between 1st April and 1st October, 2007. Informed oral consent was sought and obtained from participants before inclusion in the study. The women were assured of utmost confidentiality, and their identities were not required on the questionnaire. 29 women out of 285 declined consent giving a response rate of $89.8 \%$. The method of data collection was an exit interview of women who gave verbal consent, using an interviewer-administered structured questionnaire. Information obtained included demographic profile, contraceptive counseling received, onset of menstruation, initiation of coitus, current contraceptive use and when initiated, reasons for non-contraceptive use, and reproductive goals. Data generated from the study were keyed into the Epi info version 3.5.1 (August 13, 2008) statistical software. Frequency rates and percentages were calculated according to designated variables. Test of association, using the chi square, was calculated for demographic/reproductive variables and contraceptive use. For binary variables, strength of association was calculated using the odds ratio (OR) with a $95 \%$ confidence interval (CI) of the OR in parentheses. Multivariable analysis was done through modeling using multiple linear regression, with association deduced from correlation coefficients $\left(\mathrm{r}^{2}\right)$ of the entire model and the various coefficients of the outcome variables. All outcome variables in these situations were regarded as nominal. Significance test was obtained by analysis of variance with significance level established at $P$ value $<0.05$.

\section{Results}

The study involved 256 women, with 60 reports of current contraceptive use; giving a contraceptive prevalence of $23.4 \%$. $8(3.2 \%)$ women initiated contraception within 2 days of delivery, before discharge from hospital (intrauterine device, $2.4 \%$; sterilization, $0.8 \%$ ). The commonest method of contraceptive used was the condom, 5.5\%; other methods were intrauterine device (IUD), 4.7\%; minipill and implant, 3.1\% each; abstinence in the first six months, $1.6 \%$; lactational amenorrhoea (LAM) and sterilization, $0.8 \%$ each. There was no report of vasectomy as a method of contraception. The majority of women $(75.8 \%)$ delivered in the hospital. Other places of delivery were at the traditional birth attendant (17.2\%), home (5.5\%), and church $(1.6 \%)$. Missed opportunity for contraceptive counseling was high (antenatal, 44.5\%; postnatal, 49.2\%). Unmet contraceptive need for women who had completed their family was $65.5 \%$; and for those who desired to space their family, was $78.9 \%$. 
Women who had antenatal counseling were significantly more likely to use contraceptives than those who did not have counseling (OR 0.29; 95\% CI 0.14-0.59; $P=0.0002$ ). Also, women who had postnatal counseling were significantly more likely to use contraception than those who did not (OR 0.18; 95\% CI 0.08-0.38; $P=0.0000002$ ). Other variables significantly associated with contraceptive use were parity $(P=0.0231)$, infant feeding method $(P=0.0116)$, and reproductive goal $(P=0.0303)$. Women who had tertiary education were significantly more likely to use contraception than those who had less education (OR 0.54; 95\% CI 0.28 $1.04 ; P=0.0470)$. Although the proportion of non-Christians who used contraception was higher than in Christians, this difference was not statistically significant (OR 1.44; $95 \%$ CI 0.47-4.28; $P=0.4706$ ) (see Table 1). Linear regression analysis showed that caesarean section (CS) and episiotomy as modes of deliveries had direct relationship with initiation of coitus ( $r^{2}=0.439$ and 0.504 respectively); implying that delay in initiation of coitus by 1 month is linked to an interval of 0.439 and 0.504 month after CS and episiotomy respectively; all other factors remaining constant. Instrumental vaginal deliveries (IVDs) and spontaneous vaginal deliveries (SVDs) demonstrated inverse relationships with initiation of coitus $\left(\mathrm{r}^{2}=-1.670\right.$ and -0.133$)$, indicating that earlier initiation of coitus by 1 month is linked to an interval of 1.670 and 0.133 month after IVD and SVD respectively. The correlation between initiation of coitus and mode of delivery was not significant $(P=0.2090)$. Concerning residence after childbirth, staying at home and with in-laws showed direct relationships with initiation of coitus $\left(\mathrm{r}^{2}=0.208\right.$ and 10.750 respectively). The implication is that delay in initiation of coitus by 1 month can be linked to a 0.208 and 10.750 month stay at home and with in-laws respectively. Other places of residence showed inverse relationships with the exposure variable: such that earlier initiation of coitus by 1 month can be linked to a month's stay with mother $\left(r^{2}=-0.973\right)$; while earlier initiation of coitus by 1 month can be linked to a 5-month stay with aunt $\left(\mathrm{r}^{2}=-5.235\right)$. The correlation between initiation of coitus and residence after childbirth was not significant $(P=0.9623)$ (See Table 2). The number of women involved with sexual abstinence showed decreasing trend with increasing months after childbirth. Initiation of coitus was significantly associated with resumption of menstruation $(P<0.0001)$ and non-contraceptive use $(P=0.0089)$ (see Table 3). Reasons for non-contraceptive use included personal objection, which was related to issues of acceptability such as: medical concerns of side effects (15.1\%), psychological concern of future fertility $(10.2 \%)$,
Table I Profile of 256 women surveyed about contraceptive use ( $\mathrm{n}=$ number)

\begin{tabular}{|c|c|c|}
\hline Variables (n; \%) & Non-users & Users \\
\hline Age (years) & Row percentage & \\
\hline$<20$ & $24(85.7)$ & $4(14.3)$ \\
\hline $30-39$ & I $48(74.0)$ & $52(26.0)$ \\
\hline$>39$ & $24(85.7)$ & $4(14.3)$ \\
\hline \multicolumn{3}{|l|}{$\chi^{2}=3.35 ; P=0.1877$} \\
\hline \multicolumn{3}{|l|}{ Marital status } \\
\hline Married & I $72(77.5)$ & $50(22.5)$ \\
\hline Not married & $10(83.3)$ & $2(16.7)$ \\
\hline Widow/divorced & $14(63.6)$ & $8(36.4)$ \\
\hline \multicolumn{3}{|l|}{$\chi^{2}=2.46 ; P=0.2925$} \\
\hline I & $68(87.2)$ & $10(12.8)$ \\
\hline $2-4$ & $102(70.8)$ & $42(29.2)$ \\
\hline$>4$ & $26(76.5)$ & $8(23.5)$ \\
\hline \multicolumn{3}{|l|}{$\chi^{2}=7.53 ; P=0.023 I^{a}$} \\
\hline \multicolumn{3}{|l|}{ Education } \\
\hline Tertiary & $104(72.2)$ & $40(27.8)$ \\
\hline$\leq$ Secondary & $92(82.1)$ & $20(17.9)$ \\
\hline \multicolumn{3}{|c|}{$\chi^{2}=3.94 ; \mathrm{P}=0.0470 . \mathrm{OR}=0.54 .95 \% \mathrm{Cl}=(0.28<\mathrm{OR}<\mathrm{I} .04)$} \\
\hline Christianity & $182(77.1)$ & $54(22.9)$ \\
\hline Others & $14(70.0)$ & $6(30.0)$ \\
\hline \multicolumn{3}{|c|}{$\begin{array}{l}\chi^{2}=0.52 ; P=0.4706 . O R=1.44 .95 \% C l=(0.47<O R<4.28) \\
\text { Antenatal counseling }\end{array}$} \\
\hline Given & $96(67.6)$ & $46(32.4)$ \\
\hline Not given & $100(87.7)$ & $14(12.3)$ \\
\hline \multicolumn{3}{|c|}{$\chi^{2}=14.26 ; P=0.0002 .^{a}$ OR $=0.29 .95 \% \mathrm{Cl}=(0.14<\mathrm{OR}<0.59)$} \\
\hline Given & $82(63.1)$ & $48(36.9)$ \\
\hline Not given & $114(90.5)$ & $12(9.5)$ \\
\hline \multicolumn{3}{|c|}{$\chi^{2}=26.77 ; \mathrm{P}=0.0000002 .^{\mathrm{a}} \mathrm{OR}=0.18 .95 \% \mathrm{Cl}=(0.08<\mathrm{OR}<0.38)$} \\
\hline Exclusive breast feeding & $104(8 \mid .7)$ & $30(18.3)$ \\
\hline Supplementary feeds & $22(73.9)$ & $12(26.1)$ \\
\hline Complimentary feeds & $10(60.9)$ & $18(39.1)$ \\
\hline \multicolumn{3}{|l|}{$\chi^{2}=8.91 ; P=0.0116^{a}$} \\
\hline Completed family & $38(65.5)$ & $20(34.5)$ \\
\hline Desire more children & $150(78.9)$ & $40(2 I . I)$ \\
\hline Uncertain & $8(100)$ & $0(0.0)$ \\
\hline$\chi^{2}=6.99 ; P=0.0303^{a}$ & & \\
\hline
\end{tabular}

Notes: Chi-square test $\left(\chi^{2}\right)$ was used for testing significance. For binary variables, strength of association was calculated using the odds ratio (OR) with a $95 \%$ confidence interval $(\mathrm{Cl})$ of the $\mathrm{OR}$ in parentheses. Epi info version 3.5. I (August I3, 2008) was used on these summary tables. Outcome variables were all regarded as nominal, not ordinal.

${ }^{\text {aSignificant. }}$

effects on libido/vaginal dryness (6.4\%), and fear of loss of body parts in the afterlife following surgical contraception (5.0\%). Other reasons included lack of awareness, $21.1 \%$; need for spousal permission, $10.9 \%$; no coitus (abstinence) in the past 6 months, 3.1\%; religious bias and no reason, $1.6 \%$ each. 
Table 2 Factors affecting initiation of coital activity among 256 women $(\mathrm{n}=$ number; $(\%))$

\begin{tabular}{|c|c|c|c|c|c|c|}
\hline \multicolumn{2}{|c|}{$\begin{array}{l}\text { Initiation } \\
\text { of coitus }\end{array}$} & \multicolumn{4}{|c|}{$\begin{array}{l}\text { Demographic } \\
\text { variables }\end{array}$} & \multirow[t]{3}{*}{$\begin{array}{l}\text { Correlation } \\
\text { coefficient }\end{array}$} \\
\hline \multicolumn{2}{|c|}{ Months } & \multicolumn{4}{|c|}{ Mode of delivery (Row\%) } & \\
\hline & & CS & Episiotomy & IVD & SVD & \\
\hline I & $48(18.8)$ & $6(12.5)$ & $4(11.1)$ & $0(0.0)$ & $38(22.9)$ & $P=0.2090$ \\
\hline 2 & $60(23.4)$ & $12(25.0)$ & $12(33.3)$ & $4(66.7)$ & $32(19.3)$ & $r^{2}=0.45$ \\
\hline 3 & $46(18.0)$ & $4(8.3)$ & $8(22.2)$ & $0(0.0)$ & $34(20.5)$ & \\
\hline 4 & $12(4.7)$ & $8(16.7)$ & $0(0.0)$ & $0(0.0)$ & $4(2.4)$ & \\
\hline 5 & $4(1.5)$ & $2(4.2)$ & $0(0.0)$ & $0(0.0)$ & $2(1.2)$ & \\
\hline $6-12$ & $86(33.6)$ & $16(33.3)$ & $12(33.3)$ & $2(2.3)$ & $56(33.7)$ & \\
\hline \multirow[t]{4}{*}{ Total } & $(n=256)$ & $48(18.8)$ & $36(14.1)$ & $6(2.3)$ & $166(61.7)$ & \\
\hline & $r^{2}$ & 0.439 & 0.504 & -1.670 & -0.133 & Constant $=2.302$ \\
\hline & & \multicolumn{4}{|c|}{ Residence after delivery } & \\
\hline & & Home & In-laws & Mother & Auntie & \\
\hline I & $48(18.8)$ & $34(17.9)$ & $2(20.0)$ & $10(20.8)$ & $2(25.0)$ & $P=0.9623$ \\
\hline 2 & $60(23.4)$ & $50(26.3)$ & $2(20.0)$ & $6(12.5)$ & $2(25.0)$ & $r^{2}=0.97$ \\
\hline 3 & $46(18.0)$ & 34 (17.9) & $2(20.0)$ & $8(16.7)$ & $2(25.0)$ & \\
\hline 4 & $12(4.7)$ & $12(6.3)$ & $0(0.0)$ & $0(0.0)$ & $0(0.0)$ & \\
\hline 5 & $4(1.5)$ & $2(1.0)$ & $0(0.0)$ & $2(4.2)$ & $0(0.0)$ & \\
\hline \multirow[t]{3}{*}{$6-12$} & $86(33.6)$ & $58(30.5)$ & $4(40.0)$ & $22(45.8)$ & $2(25.0)$ & \\
\hline & Total & $190(72.4)$ & $10(3.9)$ & $48(18.8)$ & $8(3.1)$ & \\
\hline & $r^{2}$ & -0.208 & 10.750 & -0.973 & -5.235 & Constant $=6.928$ \\
\hline
\end{tabular}

Notes: Measure of association was obtained by getting the correlation coefficients from multiple linear regressions and modeling with the various coefficients of the variable in this regard. Positive coefficients give a direct and a negative coefficient an inverse relationship with the outcome variable. Note that initiation of coitus is regarded as numeric values in months.

Abbreviations: $\mathrm{r}^{2}$, correlation coefficient; CS, caesarean section; IVD, instrumental vaginal delivery; SVD, spontaneous vaginal delivery.

\section{Discussion}

At current fertility levels, a woman in Nigeria will have an average of 5.7 children during her lifetime. ${ }^{7}$ This is a dangerous trend that needs to be reversed. The opportunity for intervention presents itself when a woman in the process of childbirth seeks for attendance (whether skilled or unskilled). Contraceptive prevalence in this study was $23.4 \%$. Only $3.2 \%$ of women left the hospital with a contraceptive method after delivery. This finding is similar to that reported from Kenya. ${ }^{3}$ The methods used by women in the immediate postpartum period were IUD and sterilization. Postpartum intrauterine device (PPIUD) insertion requires special training and is not widely available as a contraceptive option. The setting of the study is a training center for PPIUD, which is provided as a contraceptive method to eligible women who deliver in the hospital. Only 2 women who had completed their family consented to puerperal sterilization. The low rate of female sterilization is not surprising, as aversion to this method has been observed in previous studies. ${ }^{8,9}$ The male condom was the commonest method used by women in this study followed by the IUD, injectables and implants/minipill, in that order. According to the recent Nigeria Demographic Health Survey (NDHS) 2003, the condom is reported to be the main method known and used by Nigerian women of reproductive age. ${ }^{7}$
The extensive social marketing of condoms in response to the HIV epidemic, with the active involvement of both government and non-governmental organizations, has been responsible for this increased awareness and subsequent increase in condom contraception use. Condoms are also the most preferred choice for postpartum contraception, especially for educated women with high parity. ${ }^{7}$ However, a previous study from this center showed that the commonest contraceptive method used by family planning clients were the IUD and implants. ${ }^{8}$ The commonest method of infant feeding was exclusive breastfeeding, but only $0.8 \%$ used lactational amenorrhea method (LAM). The LAM is an effective, natural method of family planning for postpartum women, who fulfill the criteria for use. ${ }^{10}$ In developing countries where there is a strong bias on the part of both providers and women against contraceptive technologies, the introduction of LAM into existing family planning services could fill an important need of promoting breastfeeding, while providing opportunity for women to use an effective modern method of contraception before fecundity returns. ${ }^{6,11}$ Male sterilization was not a method of contraception used by women surveyed. Although the procedure is simple, safe, and effective, it is not readily accepted as a method of fertility control in Nigeria. ${ }^{12,13}$ 
Table 3 Initiation of coitus and susceptibility to pregnancy

\begin{tabular}{llll}
\hline \multicolumn{3}{l}{ Initiation of coitus } \\
\hline Months & \multicolumn{3}{l}{ Resumption of menstruation } \\
\cline { 3 - 4 } & \multicolumn{2}{l}{ Yes } & No \\
\hline 1 & $48(18.8)$ & $32(66.7)$ & $16(33.3)$ \\
2 & $60(23.4)$ & $46(76.7)$ & $14(23.3)$ \\
3 & $46(18.0)$ & $42(91.3)$ & $4(8.7)$ \\
4 & $12(4.7)$ & $10(83.3)$ & $2(16.7)$ \\
5 & $4(1.5)$ & $4(100)$ & $0(0.0)$ \\
$6-12$ & $86(33.6)$ & $26(30.2)$ & $60(0.0)$ \\
Total & & $160(62.5)$ & $96(37.5)$ \\
$\chi^{2}=\mid 29.90 ; P<0.000 I^{\text {a }}$ & &
\end{tabular}

$\chi^{2}=129.90 ; P<\left.0.000\right|^{a}$

\begin{tabular}{llll} 
& & \multicolumn{2}{l}{ Current contraceptive use } \\
\cline { 3 - 4 } & & None & Yes \\
\hline 1 & $48(18.8)$ & $34(70.8)$ & $14(29.2)$ \\
2 & $60(23.4)$ & $38(63.3)$ & $22(36.7)$ \\
3 & $46(18.0)$ & $36(78.3)$ & $10(21.7)$ \\
4 & $12(4.7)$ & $10(83.3)$ & $2(16.7)$ \\
5 & $4(1.5)$ & $2(50.0)$ & $2(50.0)$ \\
$6-12$ & $86(33.6)$ & $76(88.4)$ & $10(11.6)$ \\
Total & & $196(76.6)$ & $60(23.4)$ \\
$\chi^{2}=15.37 ; P=0.0089^{a}$ & & \\
${ }^{2}$ Significant. & &
\end{tabular}

The profile of women most significantly associated with current contraceptive use after childbirth was receipt of family planning counseling. However, missed opportunity for counseling was high. All women who delivered outside the hospital setting did not receive antenatal contraceptive counseling. In Nigeria, two thirds of births occur at home and $71 \%$ do not receive postnatal care. ${ }^{7}$ In many societies, women typically do not return to the hospital for a postnatal checkup unless they are feeling ill or have complications. ${ }^{14}$ Antenatal and postnatal counseling where offered have been associated with significant contraceptive use. ${ }^{15-17}$ Postnatal counseling was a better determinant of contraceptive use than antenatal counseling because it provided immediate opportunity for service provision. Organized outreach to places of delivery outside the hospital and home visits by trained community health extension workers may reduce missed opportunity for increasing family planning acceptance and use through counseling. Other factors found in this study to be associated with significant contraceptive use were parity greater than one, tertiary educational attainment, introduction of complementary infant feeds, and the reproductive goal of completed family. The reproductive goals of women showed that they would like to regulate their fertility, either by preventing or spacing future pregnancies. However, unmet contraceptive need was high for women who would like to regulate their fertility. None of the women that were uncertain of their reproductive goal used any method of contraception.
Even where postpartum family planning programs are available, many factors can limit their success. Primary among them is poor integration of these programs into existing maternal and child health services. ${ }^{18}$ Integration of reproductive health services is the offering of two or more services at the same facility during the same operating hours, with the provider of one service actively encouraging women to consider using other services during the same visit. ${ }^{19}$ There was no integration of services at the setting used for the conduct of this study. Poor integration of services was inferred from the response of women during exit interview at the Immunization Clinic. Postnatal counseling was documented in a third of all women surveyed. Although the women came for child immunization, they should have been actively offered family planning counseling and encouraged to use contraception at the family planning clinic, which was just next door to this facility. Strategies to improve contraceptive prevalence for women after pregnancy through targeted counseling should be given priority.

In the absence of contraception, the probability of pregnancy is related to the regularity of sexual intercourse. The information on initiation of intercourse after childbirth is important for the refinement of the measurement of exposure to pregnancy. The visible sign of return of fertility after childbirth is the resumption of menstruation, which is usually preceded by ovulation. This study showed that the period of voluntary sexual inactivity after childbirth was decreasing with increasing months; while the duration of postpartum amenorrhea was decreasing with increasing months. The relationship between initiation of coitus and resumption of menstruation was significant. This suggests high susceptibility to pregnancy, especially as initiation of coitus was significantly associated with non-contraceptive use. Initiation of contraceptive use has been reported to be unnecessary within 3 weeks of delivery. ${ }^{20}$ It should, however, be commenced before a fecund woman becomes susceptible to pregnancy, ie, before resumption of menstruation or initiation of coitus.

Female coital activity during the puerperium has been reported to be motivated by the endeavor to satisfy the partner and secure his faith. ${ }^{21-23}$ Linear regression analysis showed that delay in initiation of coitus was linked to a shorter interval after CS than after episiotomy; while earlier initiation of coitus was associated with a shorter interval after SVD than after IVD. This relationship was, however, not significant. The observed relationship is the expected outcome especially for women who had SVD and CS, as concerns of dyspareunia are usually less with these modes 
of delivery compared with others. When residence after childbirth was considered, delay in initiation of coitus was associated with a shorter period of stay at home than with the in-laws; while earlier initiation of coitus was linked to a shorter stay with mother than with aunt. This relationship was, however, not significant. The observed relationship may be related to the level of care and assistance received, making the environment more conducive for intimate relationships for women who stayed at home and with their mother, than for those who stayed with their in-laws and aunt.

More than 200 million women in developing countries would like to delay their next pregnancy or even stop bearing children altogether, but many of them still rely on traditional and less effective methods of contraception or use no method at all. ${ }^{24}$ Those that do not use any contraceptive method may lack access to or face barriers to using contraception. These barriers include lack of awareness, lack of access, cultural factors, religion, opposition to use by partners or family members, and fear of health risks and side effects of contraceptives. ${ }^{25}$ A major obstacle to postpartum contraceptive use in this study was personal objection. This was related to issues of acceptability of contraceptive method, such as side effects, impairment of future fertility, changes in libido/vaginal dryness, and fear of loss of body parts in the afterlife following surgical contraception. Need for spousal permission continues to be an obstacle to contraceptive uptake in Nigeria, ${ }^{7}$ as seen in this study. Studies had advocated improving spousal communication in contraceptive decision making and to involve men in the counseling process. ${ }^{26,27}$ The other major obstacle to contraceptive use was lack of awareness. This finding may reflect the fact that Cross River State is ranked as educationally disadvantaged. Women with low educational attainment in this study were less likely to use contraception. Information, a component of counseling, when given during the initial hospital visit can remove lack of awareness and other barriers to accessing the desired method of contraception. Although religious bias as a factor against contraceptive use was low, the Christian and Muslim religions have been known to actively discourage the use of modern contraception by their members. ${ }^{28,29}$

\section{Summary}

Though this study is limited by women's biases and ability to recall answers required in the questionnaire, verbal autopsy is a recognized method of data collection. ${ }^{30} 7$ years after the $2003 \mathrm{NDHS}^{7}$ this study has shown that contraceptive prevalence after childbirth, even among women visiting a health facility remains low; with significant susceptibility in fecund women to unintended pregnancy. Missed opportunity for contraceptive acceptance/use was high. Unmet contraceptive need for women who wished to regulate their fertility was high. Although exclusive breastfeeding was the main method of infant feeding, the use of LAM before initiation of a modern contraceptive was very low. The giving of antenatal and postnatal family planning counseling was associated with significant contraceptive use after childbirth. Early initiation of coitus was observed in women who had spontaneous vaginal delivery and in those who stayed with their mother. Factors associated with decreased contraceptive uptake were: extremes of reproductive age, the unmarried status, low educational attainment, low parity, uncertain reproductive goal, and the Christian religion. The main reasons for non-contraceptive use were: personal objection, lack of awareness, and need for spousal permission. Addressing these identified factors through appropriate counseling technique and mobilization of women advocacy groups can result in improved acceptance and use of modern contraceptive methods in the community. In conclusion, women who initiate coital activity or resume menstruation after childbirth should be encouraged to use a modern method of contraception to prevent an unintended pregnancy.

\section{Disclosure}

The authors report no conflicts of interest in this work.

\section{References}

1. Contraceptive technology and reproductive health update series. Training module: contraception after pregnancy. Family Health International. 2010; p. 1-48.

2. Forster DA, McLachlan HL, Rayner J, Yelland J, Gold L, Rayner S. The early postnatal period: exploring women's views, expectations and experiences of care using focus groups in Victoria, Australia. $B M C$ Pregnancy Childbirth. 2008 Jul 22;8:27.

3. Bradley J, Lynam P, Gachara M, Matwale E, Dwyer J. Unmet family planning demand: evidence from two sites in Kenya. J Obstet Gynaecol East Cent Africa. 1993;11:20-23.

4. Robey B, Ross J, Bhushan I. Meeting unmet need: new strategies. Population Rep J. 1996 Sep;43:1-35.

5. Rivera R, Solis JA. Opinion: improve family planning after pregnancy. Network. 1997;17(4):4-6.

6. Wolf M, Benson J. Meeting women's needs for post-abortion family planning: report of a Bellagio technical working group. Int J Gynaecol Obstet. 1994;45(Suppl):S1-S33.

7. National Population Commission (NPC). Federal Republic of Nigeria and ORC Macro, Nigeria Demographic and Health Survey 2003. Calverton, MD, USA: NPC and ORC Macro; 2004.

8. Itam HI, Ekabua JE. Acceptance and efficacy of norplant in Calabar. Mary Slessor J Med. 1999;2(1):54-57.

9. Fakeye O. Contraception with subdermal levonogestrel implants as an alternative to surgical contraception at Ilorin, Nigeria. Int J Gynaecol Obstet. 1991;35:331-336.

10. Schnare SM, Shulman LP. Helping women make choices that facilitate successful contraceptive use. Female Patient Supplement. 2004 Apr;13-16. 
11. van der Wijden C, Kleijnen J, van den Berk T. Lactational amenorrhea for family planning. Cochrane Database Sys Rev. 2003;4:CD001329.

12. Akinwuntan AL, Shittu OB. Voluntary vasectomy in a Nigerian: a rarity. Afr J Med Sci. 2008;37:289-290.

13. Mutihir JT, Ujah IAO, Ekwempu CC, Duru PH, Aisien OA. Acceptability of vasectomy in Jos, Northern Nigeria. Trop J Obstet Gynecol. 2004;21(1):56-57.

14. Dhaher E, Mikolajczyk RT, Maxwell AE, Krämer A. Factors associated with lack of postnatal care among Palestinian women: a cross-sectiona study of three clinics in the West Bank. BMC Pregnancy Childbirth. 2008;8:26

15. Peedicayil A. Education for contraceptive use by women after childbirth: RHL commentary (last revised: 2003 Dec 17). The WHO Reproductive Health Library. Geneva: World Health Organization; 2003.

16. Adegbola $\mathrm{O}$, Okunowo $\mathrm{A}$. Intended postpartum contraceptive use among pregnant and puerperal women at a University Teaching Hospital. Arch Gynecol Obstet. 2009;280(6):987-992.

17. Faculty of Family Planning and Reproductive Health Care. FFPRHC Guidance (Jul 2004): Contraceptive choices for breastfeeding women. J Fam Plann Reprod Health Care. 2004;30(3):181-189.

18. Barber SL. Family planning advice and postpartum contraceptive use among low-income women in Mexico. Int Fam Plan Perspect. 2007; 33(1):6-12.

19. Shears KH. Family planning and HIV integration. Fam Health Int. 2004;23:4-7.

20. Guillebaud J. Postpartum contraception. Unnecessary before three weeks. BMJ. 1993;307(6918):1560-1561.

21. von Sydow K. Sexuality during pregnancy and after childbirth: a metacontinent analysis of 59 studies. J Psychosom Res. 1999;47(1): $27-49$.
22. Zahumensky J, Sverina J, Scotter O, et al. Comparison of labor course and women's sexuality in planned and unplanned pregnancy. J Psychoson Obstet Gynaecol. 2008;29(3)159-165.

23. Barret G, Victor C. Postnatal sexual health. BMJ. 1994;309(6968): 1584-1585.

24. Singh S, Darroch JE, Vlassoff M, Nadeau J. Adding it up: the benefits of investing in sexual and reproductive health. New York: Guttmacher Institute; 2003.

25. Carr D, Khan M. The unfinished agenda: meeting the needs for family planning in less developed countries. Washington DC: Population Reference Bureau; 2004.

26. Edwards SR. The role of men in contraceptive decision-making: current knowledge and future implications. Fam Plan Perspect. 1994;26(2): 77-82.

27. Iklaki CU, Ekabua JE, Abasiattai A, Bassey EA, Itam IH. Spousal communication in contraceptive decisions among antenatal patients in Calabar, South Eastern Nigeria. Nigerian J Med. 2005;14(4): 405-407.

28. Verkuyl DAA. Two world religions and family planning. Lancet. 1993; 342:473-475.

29. Oye-Adeniran BA, Adewole IF, Umoh AV, et al. Sources of contraceptive commodities for users in Nigeria. PLoS Med. 2005;2(11):e306.

30. Byass P, Ambuoso L, Quedraogo M, Qomariyah SN. Assessing the repeatability of verbal autopsy for determining cause of death: two case studies among women of reproductive age in Burkina Faso and Indonesia. Popul Health Metr. 2009 May 5;7:6.
Open Access Journal of Contraception

\section{Publish your work in this journal}

Open Access Journal of Contraception is an international, peerreviewed, open access, online journal, publishing original research, reports, reviews and commentaries on all areas of contraception. In addition to clinical research, demographics and health-related aspects, the journal welcomes new findings in animal and preclinical studies

\section{Dovepress}

relating to understanding the biological mechanisms and practical development of new contraceptive agents. The manuscript management system is completely online and includes a very quick and fair peer-review system. Visit http://www.dovepress.com/testimonials.php to read real quotes from published authors. 